Journal of Social and Development Sciences

Vol. 2, No. 6, pp. 249-257, Dec 2011 (ISSN 2221-1152)

\title{
Weak Form Efficiency of Pakistan Stock Market using Non-Parametric Approaches
}

\author{
*Muhammad Irfan, Muhammad Saleem, Maria Irfan \\ Government College University Faisalabad, Pakistan \\ *mirfanbal@yahoo.com
}

\begin{abstract}
This paper studies the performance of Karachi Stock Exchange (KSE) of Pakistan via nonparametric approaches. The study includes the weekly open and closing prices of KSE- 100 indexes for the period of $1^{\text {st }}$ January 1999 to 31st August 2009. Several non-parametric approaches including KolmogorovSmirnov test (Lilliefors test), Ryan-Joiner test (Shapiro-Wilk), Anderson-Darling test, Phillips Perron (PP) unit root test and Runs test are used to test the conviction of the KSE stock market. All non-parametric tests graphically and numerically inform us that both return series do not follow the assumption of normality and randomness, which means rejecting the hypothesis of weak form of efficiency. Generally, results from the observed analysis strongly recommend that the Karachi Stock Market of Pakistan is not efficient.
\end{abstract}

Keywords: KSE, Normality, Randomness, Market Efficiency, Non-Parametric tests

\section{Introduction and Literature Review}

Pakistan is facing a number of troubles to stabilize its healthier economy. Since last decade, weak form of efficiency has been a burning issue in many developed and developing countries. Pakistan is one of the developing countries facing this issue; this is especially true about Karachi Stock Exchange (KSE). Efficiency is an important component for the shareholders and policymakers. Practical studies that are based on the KSE are very uncommon in Pakistan. Hussain (1996), Chakraborty (2006) and recently Irfan et al. (2010) investigated the KSE by the help of parametric tests and all of them concluded that the KSE is an inefficient stock market in Pakistan, which is an indication for the investors that the risk factor will be involved if they want to deal with the KSE because of the uncertainty of the prices in the returns. To investigate the issue, the weak form of efficiency of KSE via non-parametric methods is used in this paper and, via non-parametric tests, it is concluded that KSE is an inefficient stock market. In this section, some earlier studies show that the exploration of the weak form of efficient market hypothesis in both developed and developing countries.

For developed countries, there are numerous observed studies underline the hypothesis of market weak efficiency of stock markets. Urrutia (1995) evaluated the efficiency of the financial markets of Argentina, Brazil, Chile and Mexico. Vosvrda et al. (1998) inspected the EMH used for the Prague stock exchange market for the period of 1995 to 1997. Gilmore et al. (2003) tested the efficient market hypothesis for the period of 1995 to 2000 for three developed countries Czech Republic, Poland and Hungary. All above authors concluded that all stock markets are inefficient in weak form. For developing countries, Alam et al. (1999) checked the random walk hypothesis for four developing countries Bangladesh, Hong Kong, Sri Lanka and Taiwan. They found all the stock markets excluding Sri Lanka follow a random walk. Abeysekera (2001) examined the behavior of stock prices on the Colombo Stock Exchange (CSE) in Sri Lanka.

Three main statistical tools Runs, Autocorrelation and Co- integration tests are used to daily, weekly and monthly CSE index for the period of January 1991 to November 1996. This study pointed out that the performance of stock prices of Colombo stock exchange is not regular, which indicates that the stock exchange of Colombo is not an efficient in weak form. Moustafa (2004) checked the weak form of efficiency of the UAE financial markets. Narayan et al. (2004) observed the association among the developing countries Bangladesh, India, Pakistan and Sri Lanka by Granger causality approach. Squalli (2006) inspected the weak form market efficiency of Dubai Financial Market and the Abu Dubai Securities Market using non-parametric approach to use the daily sect oral indexes of the period of 2000 to 2005. The author concluded that both financial markets are negatively serial correlated which means the presence of bull market. Ahmed and Samad (2008) investigated the Dhaka stock market of Bangladesh to know whether the market is running efficiently or not if not then what factors involve doing so. For that purpose data of 1st quarter of the financial 
year 2004, 2005, 2006 \& 2007 have been collected to check the efficient market hypothesis. The authors also effort to analysis whether the series on the industry such as bank, insurance, service, food and allied textile really follow the normal distribution.

Non-parametric approaches and ARCH family models are used to test the hypostasis of week market efficiency. Awad and Daraghma (2009) inspected the weak form of efficiency of the Palestine Security Exchange (PSE) using both parametric: serial correlation test, Augmented Dickey Fuller (ADF) unit root test and non-parametric tests: runs test and Phillips Perron (PP) unit root test. All the tests mentioned above indicated that the PSE is an inefficient stock market. The study will be helpful for the investors who want to deal with the PSE. Recently Irfan et al. (2010) examines on the survival of weak form efficiency whether the Karachi Stock Exchange (KSE) is well-organized market or not. The sample comprises on the daily and monthly closing prices of KSE- 100 indexes. All parametric methods: Unit root test, autocorrelation tests and ARIMA model are used to test the certainty of the KSE market. In general, both return series of KSE do not follow the random walk model, which means Karachi Stock Market of Pakistan is not efficient in weak form. The analyses of the efficient market hypothesis for developing countries are summarized in Table 1. This paper is structured as follows: Section 1 provides the previous studies to check the weak form of efficiency in the stock markets of developed and developing countries. Section 2 addresses the introduction of the KSE. Section 3 gives the hypothesis of the study. Section 4 describes the methodology. Section 5 presents the empirical results. Lastly, Section 6 concludes the paper.

Table 1: Weak form of efficiency in developing countries analyzed by several researchers

\begin{tabular}{|c|c|c|c|c|}
\hline Countries & Researchers & \multicolumn{3}{|c|}{ Stock Exchange Market } \\
\hline Pakistan & Hussain (1996), Chakraborty (2006) and Irfan et al. (2010) & \multicolumn{3}{|c|}{ Karachi Stock Exchange } \\
\hline India & Poshakwale (1996), Udyog (2004) and Gupta \& Basu (2007) & \multicolumn{3}{|c|}{ Mumbai Stock Exchange } \\
\hline Bangladesh & $\begin{array}{l}\text { Mobarek and Keasey (2000), Ahmad (2002) and Hossain } \\
\text { (2004) }\end{array}$ & \multicolumn{3}{|c|}{ Dhaka Stock Exchange } \\
\hline Malaysia & Branes (1986) and Mun et al. (2008) & $\begin{array}{l}\text { Kuala } \\
\text { Exchange }\end{array}$ & Lumpur & Stock \\
\hline Sri Lanka & Abeysekera (2001) and Wickremasinghe (2007) & $\begin{array}{l}\text { Colombo } \\
\text { stock }\end{array}$ & Stock & Exchange \\
\hline
\end{tabular}

Karachi Stock Exchange: There are three main stock exchanges in Pakistan. Karachi Stock Exchange (KSE) is the largest stock market in Pakistan, which was established on September 18, 1947. Other two are Islamabad and Lahore that are inactive as compared to Karachi stock exchange. It was declared that KSE is the best performing stock market in all over the World for the year of 2002. 654 companies were listed at the end of 30 May 2008. KSE -100 is used as a benchmark Pakistani index.

Hypotheses: The study seems for confirmation whether the Karachi Stock Market follows normal distribution or not. For that purpose, we designed two hypotheses to check KSE returns are normal and random over the period. In the first hypotheses, we verified that KSE follows normal distribution or another and in the second hypothesis, whether the stock returns are random over the period or not. The null and alternative hypotheses are:

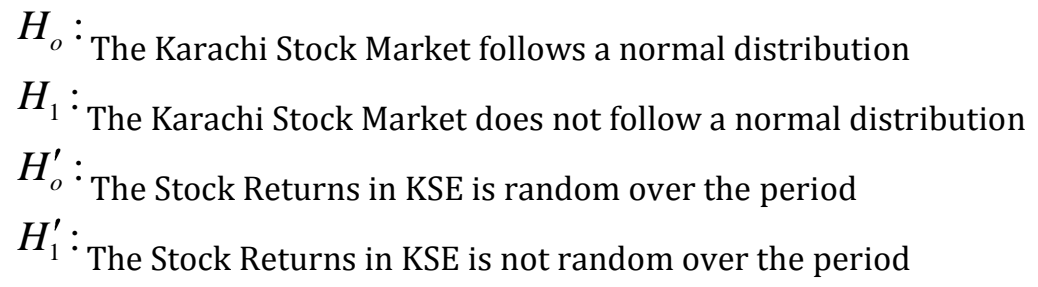

\section{Methodology}

In this section, we briefly discuss the non-parametric tests, which are used, in our study to check the efficiency of the KSE stock market: Kolmogorov-Smirnov test (Lilliefors test), Ryan-Joiner test (Shapiro-Wilk), Anderson-Darling test, Phillips Perron (PP) unit root test and Runs test. 
Data: The study includes weekly indices for ten years. We used weekly open and closing prices of the Karachi Stock Exchange for the period of $1^{\text {st }}$ January1999 to $31^{\text {st }}$ August 2009 . Weekly price for both indices were collected from yahoo finance. The sample included total 547 weekly observations for both indices. Weekly market returns are calculated from the weekly price indices as follows:

$\mathrm{R}^{t}=\ln \left(\mathrm{P}^{t} / \mathrm{P}^{t-1}\right)^{*} 100$

Where $\mathrm{R}^{t}$ is the weekly open and closing stock return series and $\mathrm{P}^{t}$ is the weekly open \& closing price indices. We estimated our results using Minitab 15, Eviews 5.1 and SPSS 15 programs.

Kolmogorov-Smirnov test: A Kolmogorov-Smirnov test (Lilliefors test) is the most well known EDF, a nonparametric test that is simply the difference between empirical and hypothetical distribution function and compared by the help of its probability value. If probability value is less than the $\alpha$ value then we reject our null hypothesis, which indicates that stock market is not efficient in weak form.

Ryan-Joiner test: This test based on the correlation between the data that is under study and the normal scores. If the test statistic falls below the critical value then we can reject our null hypothesis, which means the stock market is not an efficient stock market. This test is a similar to the Shapiro-Wilk normality test.

Anderson-Darling test: This test evaluates also the empirical cumulative distribution function under study with the expected distribution. If $\mathrm{P}$ value is less than the $\alpha$ value then we reject our null hypothesis, which indicates that stock market is not efficient.

Runs test: For the purpose of second hypothesis, whether the returns are random or not, to do so, we used runs test, which is non-parametric test. If the $Z$ value is grater than or equal to \pm 1.96 or if the probability value is less than level of significance then reject the null hypothesis at 5\% (Sharma and Kenndy (1977)).

Phillips Perron (PP) unit root test: For randomness purpose, there are two unit root tests. One is Augmented Dickey Fuller (ADF) which is parametric test (not reported in our study) another most powerful test to check the randomness is the Phillips Perron (PP) unit root test which is non parametric test. If the test statistic value is grater than critical value at $1 \%$ or probability value is less than the $\alpha$ value then we reject our null hypothesis.

\section{Results}

In time series analysis, first, we check the stationary of the returns; if the returns are not stationary then transformation is used to make it. For this purpose, Figure 1 demonstrate firstly the graph of weekly returns of both indices for the period of $1^{\text {st }}$ January1999 to $31^{\text {st }}$ August 2009 which point out evidently that data is non-stationary and continuous trend. Secondly, to make the returns of both indices stationary, we used logarithm transformation (Moustafa (2004), Saleem (2007), Awad \& Daraghma (2009) and Irfan et al. (2010). Figure 2, the weekly return series verify that the mean of the series are now about constant, which shows clearly stationary. 
Figure 1: Weekly market Index series
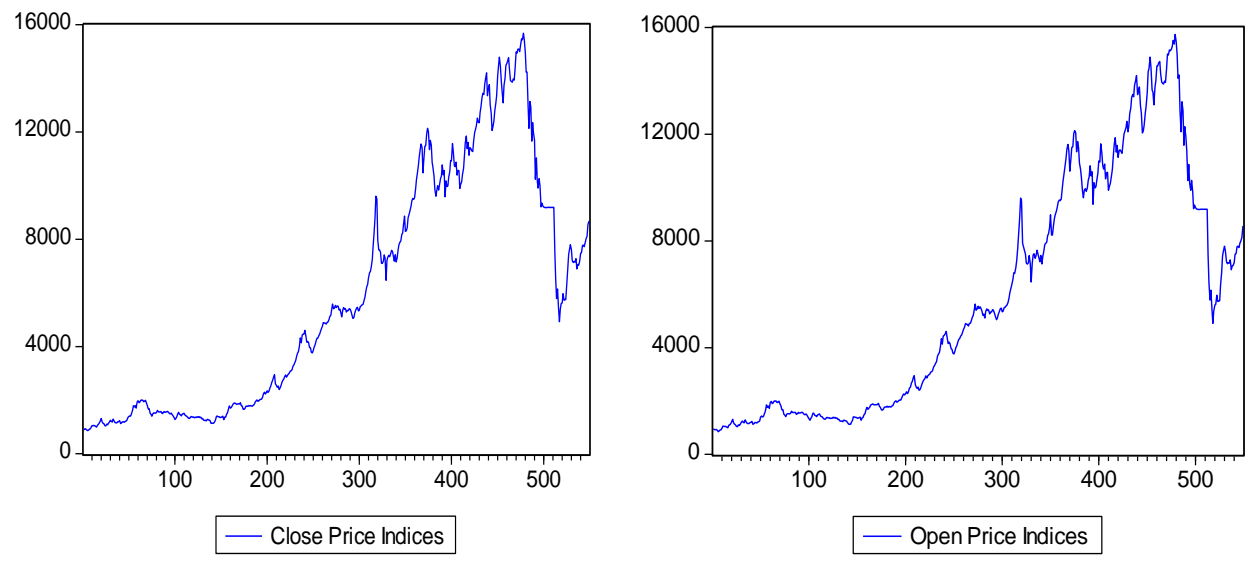

Figure 2: Weekly market Return series
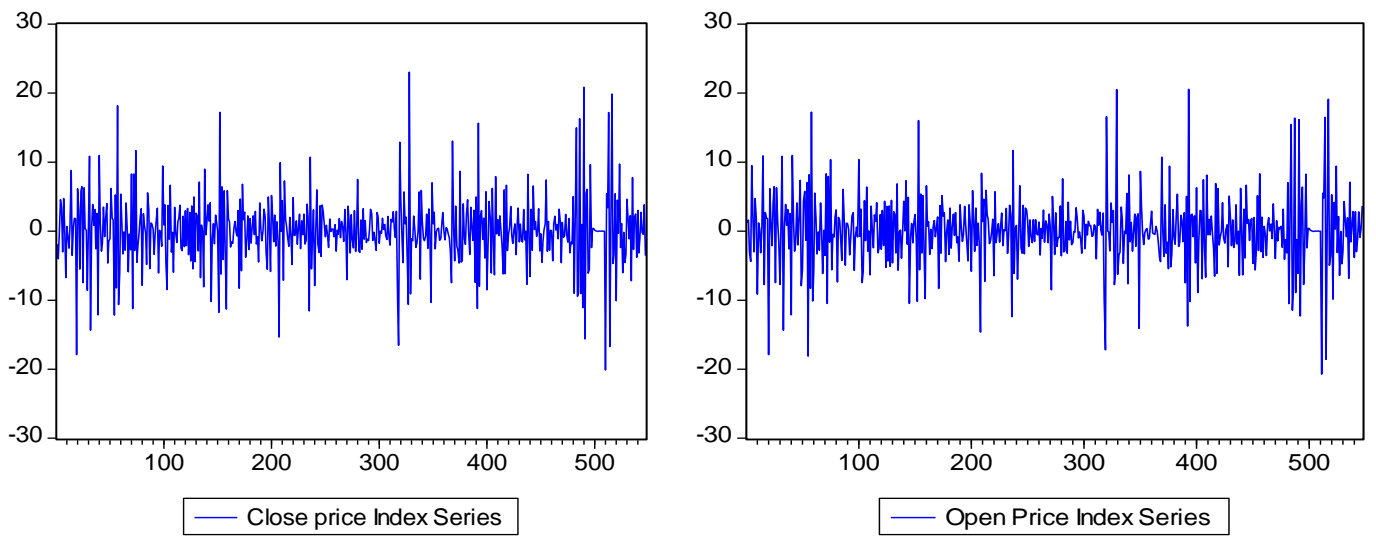

Graphically tests to check the Normality in returns: There are several graphical methods and numerical methods to check the data follows the normal distribution or not but we focused only the graphical methods and non-parametric methods only in our study (See Table 2). To check the behavior of the prices of the Karachi Stock market is to see whether the changes in returns follow the normal distribution or not. For this purpose, first we check the returns graphically with the help of histogram and box plot because we have a large sample sizes if sample size is small then we used Stem \& leaf and dot plot.

Numerically methods: Descriptive statistics and Non-parametric methods: Skewness \& kurtosis test and Kolmogorov-Smirnov tests (Lilliefors tests), Ryan-Joiner tests (Shapiro-Wilk) and Anderson-Darling tests are used to test the hypothesis of normality. We begin; the descriptive Statistics of the log of the weekly stock market returns are measured and presented in Table 3. The return series of both close and open prices are leptokurtic because of its large kurtosis value, which rejects the normality at the $1 \%$ level. The confirmation of positive skewness in both returns is comparable to the findings of Irfan et al. (2010) in Pakistan stock market but their positive skewness coefficients of daily and monthly KSE is $(0.32 \& 0.07)$ and Mobarek and Keasey (2000) in Dhaka stock market of Bangladesh who get the positive skeweness (1.203) is a larger quantity as compare to our skewness coefficients. Skewness and kurtosis test for both open and close prices gives the values $172.818 \& 228.828$ respectively, which are the greater than the critical value at 2 degree of freedom means also reject the null hypothesis of normality.

Generally, a distribution is said to be normal when the value of skewness and kurtosis are 0 and 3 respectively. Figure $3,4 \& 5$ provides a general overview of the data with the help of histogram and box plot which is simply a graphically test to check the normality when we have large sample size. Graphically analysis for both returns of KSE for the period of $1^{\text {st }}$ January 1999 to $31^{\text {st }}$ August 2009, which clearly demonstrates 
that the returns are non-symmetric accordingly to the Jarque and Bera test (1980), which is a parametric approach to test the normality. Same results are produced in Figure 6, which shows clear reject the null hypothesis of normality according to QQ plots because the return values do not cluster around the straight line, if the points cluster around the straight line then we say that the data will be normal otherwise not. In accordance with the Sharma \& Kennedy (1977), Saleem (2007) and Irfan et al. (2010)'s finding that both returns were non-symmetric, leptokurtic with positive skewness. In other words, Skewness and Kurtosis values for both return series on the KSE indicate that the distribution is not normal. Hence we conclude in the end that KSE is not efficient in weak form because the rejection of hypothesis of normality.

Table 2: Graphical methods and non-parametric methods to check the normality and randomness assumption

\begin{tabular}{lll}
\hline & Graphical methods & Numerical methods \\
\hline Descriptive & Histogram and Box Plot & Skewness and Kurtosis test \\
Theory based tests & Quantile - Quantile & Kolmogorov-Smirnov test (Lilliefors test) \\
& (Q-Q) plot & Ryan-Joiner test (Shapiro-Wilk) \\
& & Anderson-Darling test (AD test) \\
& Runs test \\
& Phillips-Perron unit root test (PP test) \\
\hline
\end{tabular}

Table 3: Descriptive Statistics of log of the weekly market returns

\begin{tabular}{llll}
\hline & & \multicolumn{2}{c}{ Statistic } \\
\hline Variables & Description & Open Price Index & Close Price Index \\
\hline \multirow{4}{*}{ Weekly Market Return } & 547 & 547 \\
$R_{t}$ & Number of observations & 0.013263 & -0.001894 \\
& Mean & 0.033609 & 0.003057 \\
& Median & 20.54773 & 23.03242 \\
& Minimum & -20.69267 & -20.09765 \\
& Standard deviation & 5.202212 & 5.104929 \\
& Skewness & 0.053407 & 0.196131 \\
\hline
\end{tabular}

* Skewness and Kurtosis test reject the null hypothesis of normality. Where Skewness and Kurtosis test is defined as: $n\left[\frac{\text { skewness }^{2}}{6}-\frac{(\text { kurtosis }-3)^{2}}{24}\right] \square \chi^{2}(2)$. Here $\mathrm{n}$ is the total number of observations under study.

Figure 3: Descriptive statistics for open prices of KSE

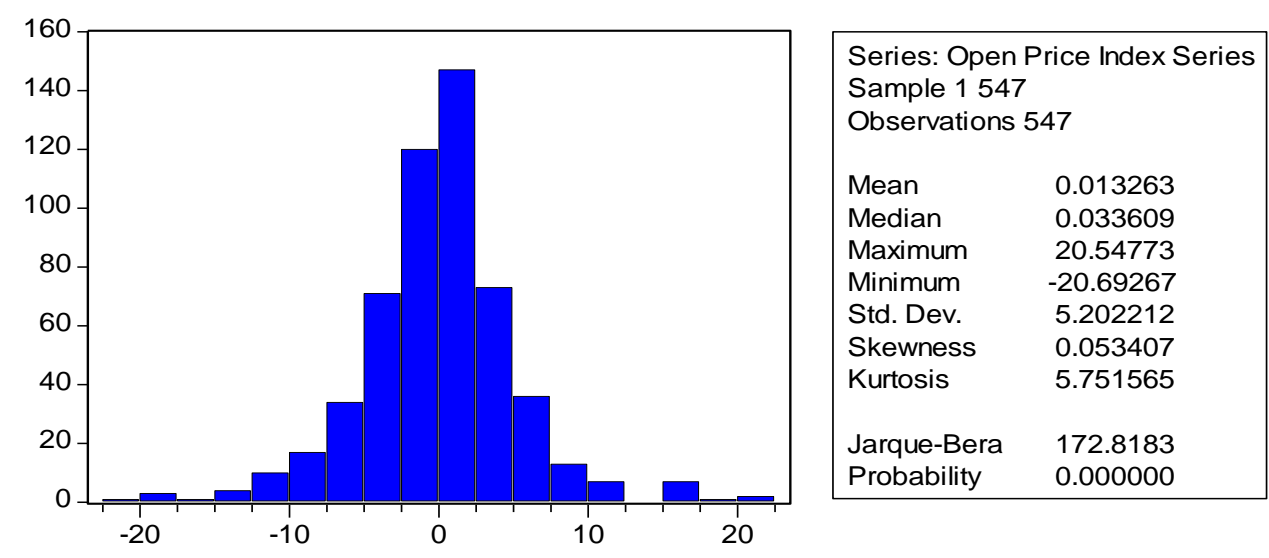


Figure 4: Descriptive statistics for close prices of KSE

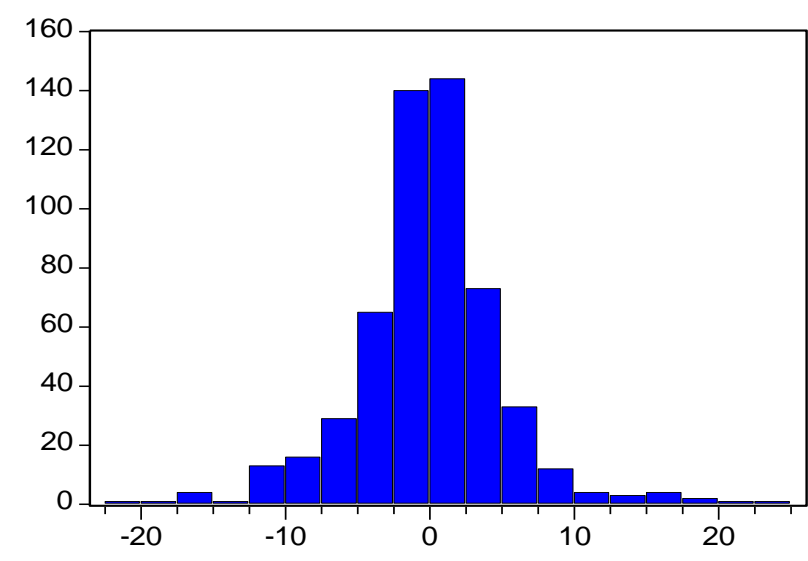

Series: Close Price Index Series Sample 1547

Observations 547

Mean $\quad-0.001894$

Median $\quad 0.003057$

Maximum 23.03242

Minimum $\quad-20.09765$

Std. Dev. $\quad 5.104929$

Skewness $\quad 0.196131$

Kurtosis $\quad 6.144217$

Jarque-Bera $\quad 228.8276$

Probability $\quad 0.000000$

Figure 5: Box plot of weekly open and close prices returns

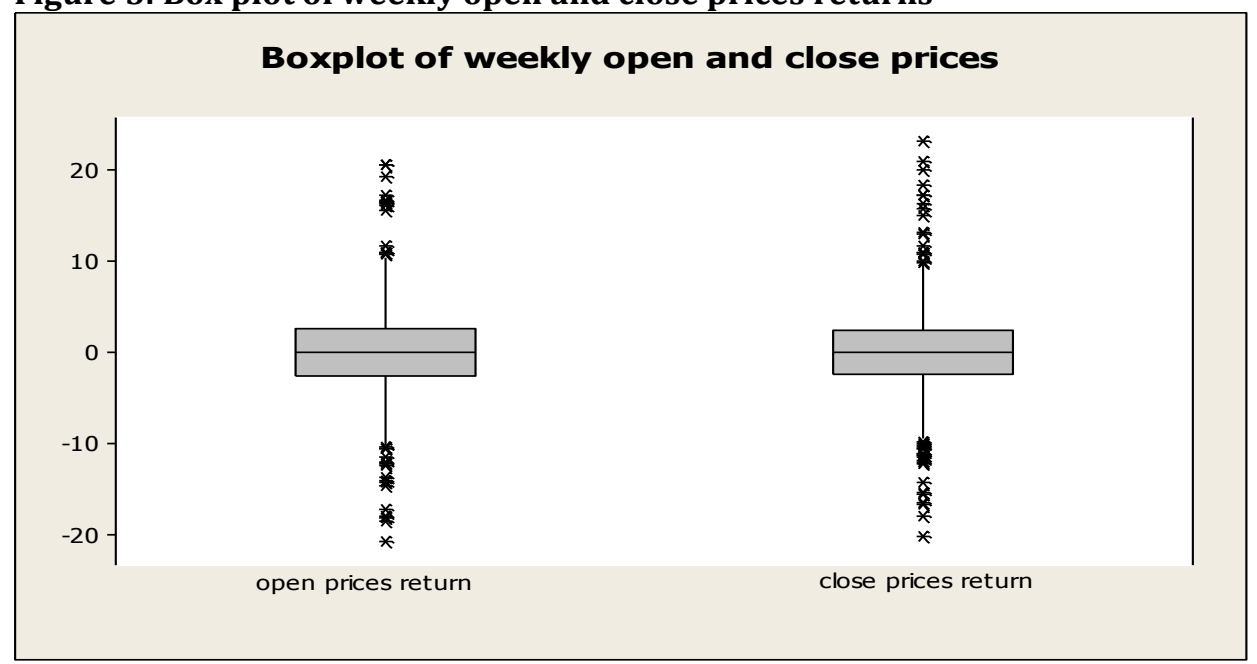

Figure 6: The Quantile- Quantile (Q-Q) for open and close prices of KSE
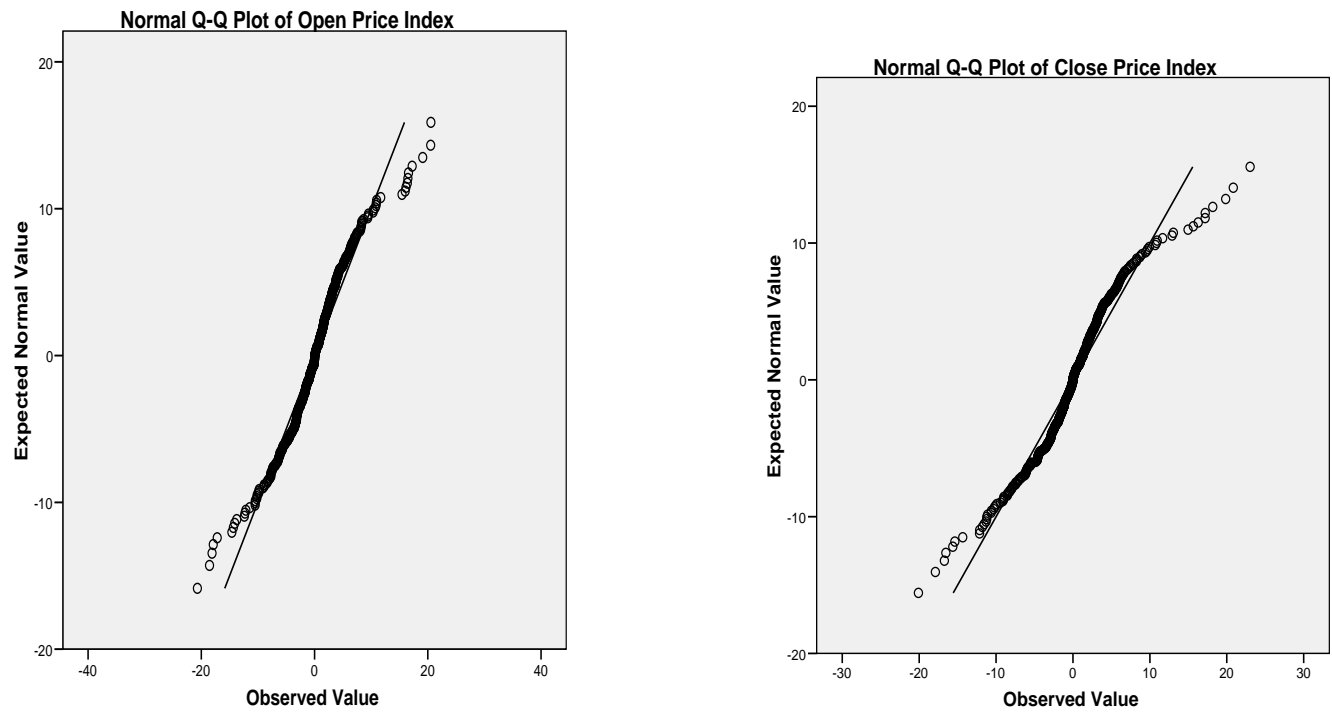
Detrended Normal Q-Q Plot of Close Price Index

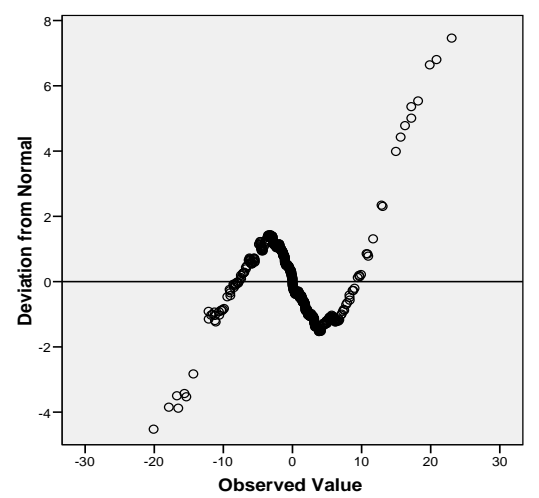

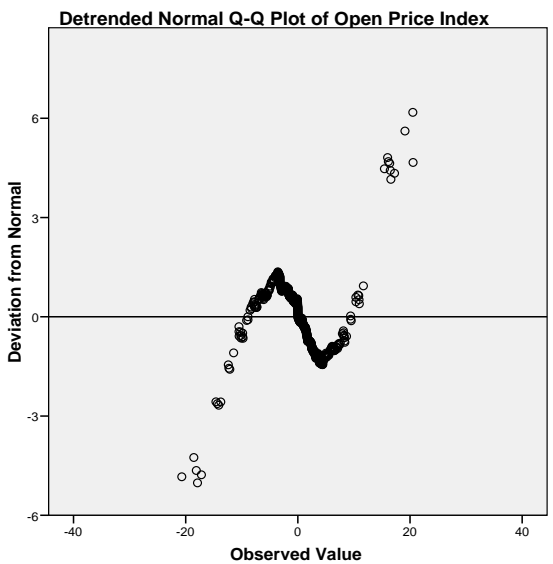

Numerical analysis to investigation of normality in returns: Kolmogorov-Smirnov tests (Lilliefors tests), Ryan-Joiner tests (Shapiro-Wilk) and Anderson-Darling tests (AD test) are all non-parametric approaches to confirm the assumption of normality in our data sets. In Kolmogorov-Smirnov test, we assess the observed cumulative distribution function for a variable (weekly open and close prices under consideration) with a specified theoretical distribution, which may be normal, uniform, Poisson or exponential but in our study we take normal distribution rather than other (Table 4). Results clearly indicate that both indices do not follow the normality. In Table 5, same results indicated by both Ryan-Joiner test and Anderson-Darling test for both tenor periods reject the null hypothesis of normality which means that both returns don't follow the normal distribution. Therefore, all non-parametric tests showed that both returns are non-normal. In agreement with the Ahmed and Samad (2008) investigated the Dhaka stock market of Bangladesh and Awad and Daraghma (2009) inspected the weak form of efficiency of the Palestine Security Exchange (PSE) are non normal by both parametric and non parametric methods. Thus, we conclude that KSE is not an efficient market because returns do not follow the normal.

To test the second hypothesis of our study that returns are random over the period or not, we used firstly the usual Phillips-Perron (PP) test is applied to return series of weekly open and close prices of KSE. Table 6 reports the results of the PP test. Since the PP test statistic for both returns are less than the critical value at $1 \%$ or by the help of probability value, the null hypothesis of a unit root test is rejected at $1 \%$ level which means returns are non random. Thus, we say that KSE is not an efficient stock market of Pakistan. All nonparametric tests reject the hypothesis of normality, which is defined already in the previous section. Secondly, we used runs test to check the randomness that is purely a non-parametric approach. Table 7, shows that the test statistics $\mathrm{Z}$ of both weekly open and close returns do not fall in the critical region means the probability value of both returns $(0.000)$ is less than the level of significance that clearly indicates the rejection of the null hypothesis. These results are the equivalent to the findings of Fama (1965), Sharma \& Kennedy (1977) and Wong \& Kwong (1984) who used runs test to check the efficiency of the stock prices. Therefore, runs test shows that Karachi stock market is not efficient which means both returns are not random.

Table 4: Kolmogorov-Smirnov Goodness of Fit Test

\begin{tabular}{|c|c|c|c|}
\hline \multicolumn{2}{|c|}{ One sample Kolmogorov-Smirnov Test } & Open Price Index & Close Price Index \\
\hline \multicolumn{2}{|c|}{ Number of Observations } & 547 & 547 \\
\hline \multirow[t]{2}{*}{ Normal Parameters } & Mean & .0133 & -.0019 \\
\hline & Std. Deviation & 5.20221 & 5.10493 \\
\hline \multirow{3}{*}{$\begin{array}{lr}\text { Most } & \text { Extreme } \\
\text { Differences } & \end{array}$} & Absolute & .076 & .086 \\
\hline & Positive & .074 & .081 \\
\hline & Negative & -.076 & -.086 \\
\hline \multicolumn{2}{|l|}{ Kolmogorov-Smirnov Z } & 1.766 & 2.005 \\
\hline
\end{tabular}


Asymp. Sig. (2-tailed)

.004

.001

* Here we used Normal distribution.

Table 5: Kolmogorov-Smirnov (Shapiro-Wilk) and Anderson-Darling statistics of KSE returns

\begin{tabular}{lllllll}
\multirow{2}{*}{ KSE Returns } & \multicolumn{3}{l}{ Ryan-Junior (Shapiro-Wilk) } & \multicolumn{4}{l}{ Anderson-Darling test } \\
\cline { 2 - 7 } Open Price Index & Statistic & $\mathrm{df}$ & Sig. & Statistic & $\mathrm{df}$ & Sig. \\
Close Price Index & $* .954$ & 547 & .000 & $* 6.417$ & 547 & .000 \\
\hline
\end{tabular}

${ }^{*}$ Rejects the normality assumption in both returns with the help of probability value $(0.000)$

Table 6: Unit root test for both indices

\begin{tabular}{llll}
\hline Indexes & Phillips-Perron test & Critical value at 1\% & P-value \\
\hline Open Price Index & -247.4825 & -3.974925 & 0.0001 \\
Close Price Index & -278.9970 & -3.974925 & 0.0001 \\
\hline
\end{tabular}

Table 7: Runs test of both indices

\begin{tabular}{lll}
\hline & Open Price Index & Close Price Index \\
\hline Total Cases & 547 & 547 \\
Number of Runs & 353 & 345 \\
Z & $* 6.731$ & $* 6.039$ \\
Asymp. Sig. (2-tailed) & .000 & .000 \\
\hline
\end{tabular}

* Mean is used as a cut point

\section{Conclusion}

Weak form of efficiency is a blazing problem in many developing countries including Pakistan. In this paper, we study the performance of Karachi Stock Exchange (KSE) of Pakistan via non-parametric approaches: Kolmogorov-Smirnov tests (Lilliefors tests), Ryan-Joiner tests (Shapiro-Wilk) and Anderson-Darling test are used to check the assumption of normality and Phillips Perron (PP) unit root test and Runs test are used to test the randomness of the returns of the KSE stock market. The study includes the weekly open and closing prices of KSE- 100 indexes for the period of $1^{\text {st }}$ January1999 to $31^{\text {st }}$ August 2009. As mentioned earlier, our focused is just to check the efficiency of the KSE. For this purpose we developed two hypotheses, one is the normality assumption in the returns and the second one is to check the randomness in the returns. In the aspect of skewness and kurtosis test, both returns under study found non-normal. Same results are produced from all non-parametric tests, which also confirmed that both returns do not follow the normality and randomness hypotheses of weak form efficiency. Overall, results from the observed analysis strongly recommend that the Karachi Stock Market of Pakistan is not efficient market. These results strongly suggested that risk factor is involved in dealing with the KSE because market efficiency changes over the time.

\section{References}

Abeysekera, S. P. (2001). Efficient Markets Hypothesis and the Emerging Capital Market in Sri Lanka: Evidence from the Colombo Stock Exchange - A Note. Journal of Business Finance \& Accounting, 28(12), 239-261.

Ahmad, F. (2002). Market Efficiency in Emerging Stock Markets: The Case of Dhaka Stock Exchange.www.fgda.org/html/savings 2002-1.htm.

Ahmed, H. U. \& Samad, Q. A. (2008). Performance level of Dhaka stock market: A quantitative analysis. Daffodil International University Journal of Business and Economics, 3(1).

Alam, M, I., Hassan, T. \& Kadapakkam, P. (1999). An Application of variance Ratio Test to Five Asian Stock Markets. Review of Pacific Basin Financial Markets and Policies, 2, 301-315.

Awad, I. \& Daraghma, Z. (2009). Testing the weak form efficiency of the Palestinian securities market. International Research Journal of Finance and Economics, 3(2).

Branes, P. (1986). Thin trading and stock market efficiency: A case of the Kuala Lumpur Stock Exchange. Journal of Business Finance \& Accounting, 13(4), 609-617. 
Chakraborty, M. (2006). Market Efficiency for the Pakistan Stock Market: Evidence from the Karachi Stock Exchange. South Asia Economic Journal, 7(1), 67-81.

Fama, E. F. (1965). The behavior of stock prices. Journal of Business. 38, 34-105.

Gilmore, C. G, McManus, G. M. \& Ginette, M. (2003). Bilateral and Multilateral Cointegration Properties between the German and Central European Equity Markets. Studies in Economics and Finance 21, 4053.

Gupta, R. \& Basu, P. K. (2007). Weak form efficiency in Indian stock markets. International Business and Economics Research Journl, 6(3).

Hossain, F. (2004). Days of the Week Effect in Dhaka Stock Exchange from small Portfolios of Banking Sector. Jahangirnagar Review, Part II: Social Sciences, XXVIII, 73-82.

Hussain, F. (1996). Stock price Behaviour in an Emerging Market: A case study of Pakistan. Ph. D thesis, The Catholic University of America.

Irfan, M., Irfan, M. \& Awais, M. (2010). Investigating the weak form efficiency of an emerging market using parametric tests: Evidence from Karachi stock market of Pakistan. Electronic Journal of Applied Statistical Analysis. 3(1), 52-64.

Jarque, C. M. \& Bera, A. K. (1980). Efficient tests for normality, homoscedasticity and serial independence of regression residuals. Economics Letters, 6(3), 255-259.

Mobarek, A. \& Keasey, K. (2000). Weak-Form Market Efficiency of an Emerging Market: Evidence from Dhaka Stock Market of Bangladesh, in ENBS Conference held on Oslo, May 2000, 1-30.

Moustafa, M. A. (2004). Testing the weak form efficiency of the United Arab Emirates stock market. International Journal of Business, 9, 309-325.

Mun, H. W., Sundaram, L. \& Yin, O. S. (2008). Leverage effect and market efficiency of Kuala Lumpur Composite Index. International Journal of Business and Management, 3(4).

Narayan, N., Smyth, R. \& Nandha, M. (2004). Independence and Dynamic Linkages between the Emerging Stock Markets of South Asia. Accounting and Finance, 44, 419-440.

Poshakwale, S. (1996). Evidence on the Weak form efficiency and the day of the week effect in the Indian Stock Market. Finance India, 10(3), 605-616.

Saleem, K. (2007). Modeling Time Varying Volatility and Asymmetry of Karachi Stock Exchange (KSE). International Journal of Economic Perspectives, 1, 1-9.

Sharma, J. L. \& Kennedy, R. E. (1977). A comparative analysis of stock price behavior on the Bombay, London and New York stock exchanges. Journal of Financial and Quantitative Analysis.12, 391-413.

Squalli, J. (2006). A non-parametric assessment of weak form efficiency in the UAE financial markets. Applied Financial Economics, 16(18), 1365-1373.

Udyog, P. (2004). Test of random walk hypothesis in Indian stock market. A revisit, 28(1).

Urrutia, J. L. (1995). Tests of random walk and market efficiency for Latin American emerging markets. Journal of Financial Research, 18, 299-309.

Vosvrda, M., Filacek, J. \& Kapicka, M. (1998). The Efficient Market Hypothesis on the Pargue Stock Exchange, Workshop to ACE Phare Project Paper 95-2012-R.

Wong, K. A. \& Kwong, K. S. (1984). The behavior of Hong Kong stock prices. Applied Economics, 16, 905-917.

Wickremasinghe, G. B. (2007). Seasonality of emerging stock markets: A study using data from the Colombo stock exchange. ICFAI journal of applied finance, 13, 43-65. 